\title{
Burnout in Tourism and Hospitality SMEs: the Moderating Role of Organizational Commitment
}

Hany Hosny Sayed Abdelhamied Ahmed Mohamed Elbaz Faculty of Tourism and Hotels, University of Sadat City, Egypt

\section{Abstract}

This paper investigates the role of organisational commitment in reducing the negative influence of employees' burnout, expressed through emotional exhaustion, cynicism, and reduced professional efficacy, on tourism and hospitality SMEs' performance. Using data collected from 788 tourism and hospitality SMEs' frontline employees operating in Egypt, the findings show that a higher level of organizational commitment diminishes the negative influence of employee burnout on performance. These findings hold important implications for tourism and hospitality SMEs in the Middle-Eastern and North-African region, especially in relation to the important role organisational commitment plays in regulating burnout negative influences.

Keywords: Burnout; Organisational Commitment; Tourism and Hospitality SMEs; Egypt.

\section{Introduction}

The nature of service industry involves a constant and direct contact between employees and customers. Particularly in the tourism and hospitality industry, employees are subject to significant pressures from both managers and customers when offering their services. Consequently, issues related to stress and burnout are more likely to be prevalent in such industries (Pienaar \& Willemse 2008). Here, the term burnout was presented to explain individual's psychological response to work stressors. Pines and Aronson (1988, p.9) described burnout as "a state of physical, emotional and mental exhaustion caused by long term involvement in situations that are emotionally demanding". Maslach (1982) conceptualized burnout through three dimensions, namely: emotional exhaustion, depersonalization, and reduced personalized accomplishment. Emotional exhaustion describes the diminution of an individual's emotional resources due to a work demand or stress experienced in the work place, whereas depersonalization or cynicism describes employees' lukewarm attitude toward the job in other words, the disinterested feeling or reaction toward clients (Maslach \& Jackson, 1986). Reduced personal accomplishment refers to individuals' feelings of lack of progress at work or unsuccessful accomplishment (Maslach, Jackson, \& Leiter, 1996; Leiter \& Maslach, 2004). Studies on the importance of burnout have revealed its link to different outcomes related to organizational performance (Maslach, Schaufeli, \& Leiter 2001).

The root cause of employee burnout could be explained through the lenses of the conservation of resources theory (COR) (Hobfoll, 1989), which argues that burnout occurs when employees fail to conserve what they perceive as valued assets (Hobfoll, 2001). Such a loss is often the consequence of a disproportionate work-life balance, which would eventually lead to an increased burnout, depression, dissatisfaction and leaving intentions (Hobfoll, 2002). Naidoo et al., (2012) posit that when employees are more concerned with protecting their existing resources than seeking additional ones, they are more likely to show signs of burnout. This being said, the COR theory also acknowledge the existence of several factors that could potentially help those employees dealing with such concerns and retain their resources (Hochwarter, Ferris, Zinko, Arnell, \& James, 2007). Here, Hobfoll, (2002) explains that factors that have the potential to increase employees' social support can decrease burnout levels (Shaw, Fields, Thacker, \& Fisher 1993). In this respect, evidence showed for instance, that the 
intervention of increased means efficacy (employees' confidence in accessing the means, equipment, and materials necessary to perform the job effectively) would help employees in their resource seeking process and hence reduce burnout risks (Chen Westman, \& Eden, 2009). Similarly, individuals' perceived control, defined as the extent to which individuals feel they can influence and shape their work environment (Skinner, 1996), is also likely to decrease stress levels. In this vein, the present study argues that organizational commitments could also be amongst those external intervening factors in regulating the negative influence of burnout and therefore, attempts to investigate the moderating role of organizational commitment in reducing the negative link between employee burnout and tourism SMEs performance. The concept of the organizational commitment of employees to the organization has received considerable attention as a determinant factor for employee performance (Mathieu \& Zajac, 1990; Morrow, 1993). However, Garg and Rastogi (2006) explain that organizational commitment affects role behaviours, which would in turn, contribute to overall organizational efficiency and effectiveness. In this study, organizational commitment is argued to influence performance by affecting role behaviors related to stress issues.

The contribution of the present paper to the current literature is two-fold. First, the study provides a comprehensive insight about the influence of employees' burnout on tourism and hospitality SMEs performance. The multifaceted conceptualization of burnout concept adopted in this study (i.e. comprising the three dimensions, namely emotional exhaustion, cynicism and reduced professional efficacy) would allow the researchers to identify the effect of each dimension on performance distinctly. Investigating the three-burnout dimensions would also provide an enhanced understanding of which aspect of employees' burnout dimensions could be reduced by the moderating role of employees' commitment in such a relationship. Second, despite the crucial role the tourism and hospitality industry plays in fostering the development of Egypt, evidence form this area remain scarce, hence providing an important contextual contribution could serve as an important example for the whole Middle East and North Africa MENA region. The results will help tourism and hospitality SMEs' frontline employees and managers in developing strategies to mitigate employee' burnout issues and help to increase tourism and hospitality SMEs' performance. To address these aims, the present paper develops an integrative model investigating the moderating influence of organizational commitment on the link between employee burnout, conceptualized through emotional exhaustion, cynicism and reduced professional efficacy, and tourism and hospitality SMEs' performance. The present study tests the proposed model using a representative sample of Egyptian tourism and hospitality SMEs.

Following on from this introduction, the next section outlines the theoretical framework and hypotheses development. Thereafter, an overview of the research methods and findings is provided. Finally, the results are discussed and conclusions are drawn.

\section{Theoretical Background and Hypotheses Development Burnout and Organizational Performance}

In theory, burnout has serious negative consequences for individuals and organizations including higher turnovers, job dissatisfaction and poor performance (Han, Bonn, \& Cho 2016). In the past two decades' burnout has been emerging as a key determinant factor affecting many management practices and employee behaviors in service industry (Burgess \& Connell 2006). Burnout is perceived as a work-related 
syndrome of stress, caused by long-term engagement in situations that are emotionally demanding (Pines \& Aronson 1988). Different causes of burnout have been acknowledged. For example, Deery, Iverson, and Walsh (2002) reported that the nature of work in service industry requires high level of customers contacts, higher percentage of workloads and restricted work regulations, whereas Deery and Kinnie (2004) specified reasons such as failures to perform services according to standards, responding to customer wants/desires, or managing clients' complaints.

On the other hand, performance is a term used to portray how well an individual performs the requested tasks. Performance is crucial for both personnel and organizations as it influences, greatly decisions concerned with promotions, terminations, merit, increases, and bonuses. Naff and Crum (1999) linked the performance with the result of person's effort, willingness and wish to achieve the goal. According to Motowidlo and Van Scotter, (1994), employee performance can be conceptualised through two main dimensions, task performance and contextual performance. While the former is a behaviour linked with maintaining and servicing an organization's technical core, the latter is a function of one's interpersonal skill knowledge that supports the broader social environment in which the technical core must function.

The relationship between burnout and performance has long been investigated in different sectors. For example, Schaufeli and Buunk (2003) reported that poor performance is one of the most important consequences of job burnout. In line with this, authors found improving employees social support and emotional support reduce fatigue and emotional exhaustion and contribute to performance (Taris, 2006; Holman 2002). Similarly, emotional exhaustion was found to be associated with organizational outcomes such as personnel turnover, absenteeism and job performance (Schaufeli \& Buunk, 2003). May, Bauer and Fincham (2015) reported a negative association between school burnout and academic performance. Therefore, considering the multifaceted approach in relation to the definition of burnout adopted in this study, the first three hypotheses of this study are formulated:

H1. Employee emotional exhaustion has a negative influence on organizational performance.

H2. Employee cynicism has a negative influence on organizational performance.

H3. Employee reduced professional efficacy has a negative influence on organizational performance.

2.2. The moderating role of organizational commitment.

Hospitality and tourism organizations need employees with high commitment and low burnout levels to achieve organizational aims and targets with a low turnover rate, low absenteeism, and high-quality service and customer satisfaction (Gemlik et al.,2010). The most common definition of organizational commitment was stated by Allen and Meyer (1990, p. 14) as "a psychological state that binds the individual to the organization". Griffin et al. (2010) stated that organizational commitment is defined as the relationship between the worker and his/her company. The organizational commitment construct includes three main types, namely: affective, normative, and continuance commitment. Affective commitment refers to the employee's feelings of loyalty, identification and pride of the organisation. Contrastingly, normative commitment is defined as the "feeling of obligation to continue employment" (Meyer \& Allen, 1997, p. 11). As for continuance commitment, the latter refers to the commitment occurring because of the costs associated with work discontinuity (Meyer \& Allen, 1991). The current study focuses on affective commitment only. The literature review provides concrete evidence for the link between burnout and 
organizational commitment. Maslach (1979) stated that lower commitment is the result of burnout, as well as it increased turnover and absenteeism. Leiter (1991) has also demonstrated that emotional exhaustion is highly associated with organizational commitment. Similarly, Jackson, Turner, and Brief (1987) proposed that high levels of burnout among public service lawyers can be caused by a decline in their commitment towards their agency. In addition, Leiter and Maslach (1988) showed that burnout effects (including its three dimensions) were linked to organizational commitment amongst nurses. Likewise, Jackson, Schwab, and Schuler (1986) found that organizational commitment was the mediating variable in the relationship between burnout and both turnover and job withdrawal. In the health professional sector, Kalliath, O'driscoll, and Gillespie (1998) found a link between burnout and employees' organizational commitment. Similarly, Gemlik et al. (2010) proved that high burnout linked with reduced organizational commitment. Previously, Meyer et al. (1989) examined the relationship between affective commitments and all three measures of performance in the food service sector and found a positive association. Other studies shed light on organizational commitment as a mediator for positive performance (Shawa, Delery, \& Abdulla, 2003). Conversely, other authors found a weak relationship between organizational commitment and performance (Francesco \& Chen, 2004). Following this, Yiing \& Ahmad (2009) demonstrated that organizational commitment is not associated with employee performance. In this vein, past studies have also confirmed a modest relationship between organizational commitment and performance (Wright, 1997). Based on this discussion and on the conflicting findings regarding the link between organisational commitment, employee burnout and performance, the following hypotheses are proposed;

H4. A high level of organizational commitment reduces the impact of employee emotional exhaustion on organizational performance.

H5. A high level of organizational commitment reduces the impact of employee cynicism on organizational performance.

H6. A high level of organizational commitment reduces the impact of employee professional efficacy.

Figure 1. Theoretical framework and hypotheses

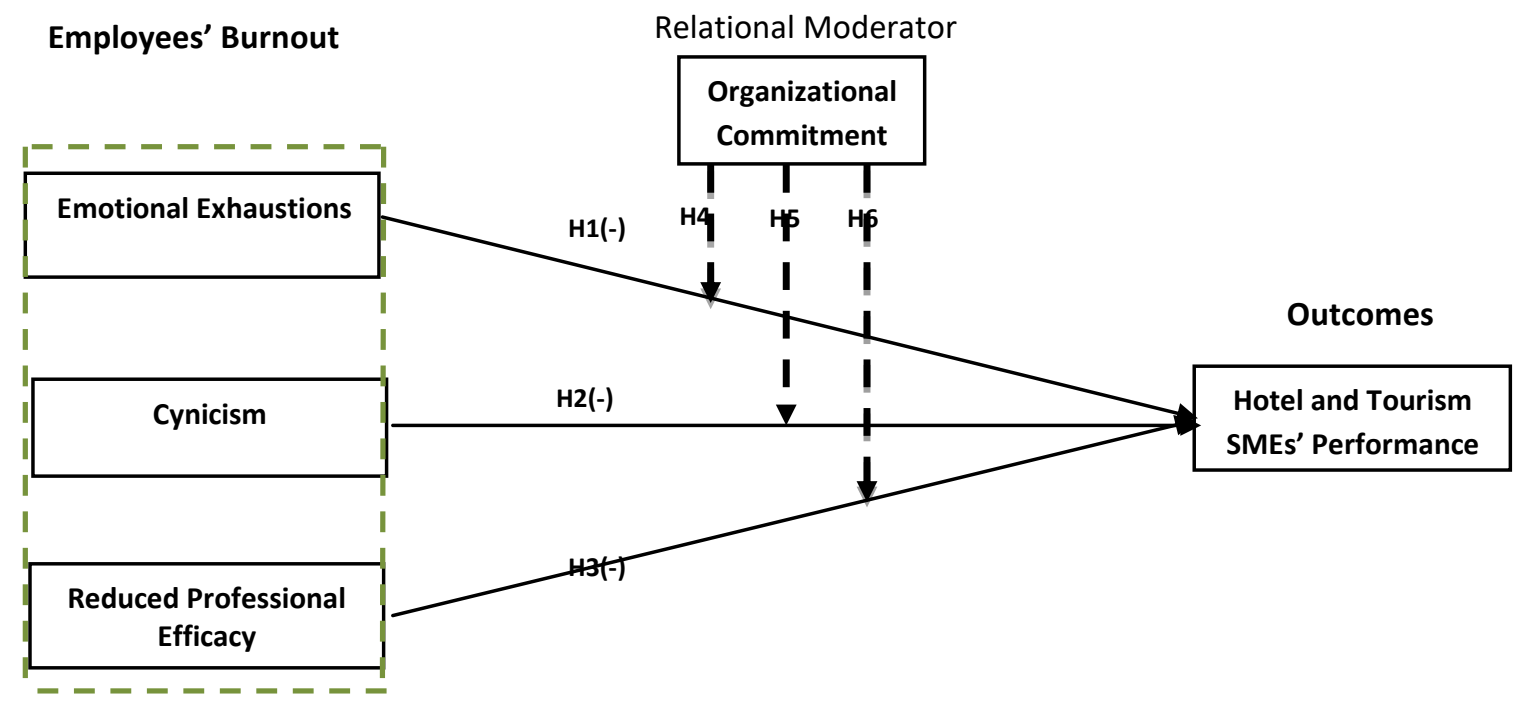

Concluding, and based on the preceding review, this paper includes organisational commitment as an interaction factor in the link between frontline employees' burnout in terms of exhaustion, cynicism and reduced professional efficacy and the 
performance of tourism and hospitality SMEs. Figure 1 shows our conceptual framework.

\section{Methods}

Drawing on random sampling strategy, the researchers collected the data from a sample includes three stars' hotels and travel agencies category (A) in major governorates in Egypt. A sample of 788 tourism and hospitality SMEs' frontline employees operating in Egypt was surveyed randomly in this study. Frontline employees of tourism and hospitality SMEs were the key informants. To gather the data, four research assistants were employed and the questionnaires were filled with the presence of the surveyors after getting the ethical approval. The process took place in May 2017. As mentioned previously, the sample included both small and medium sized hotels (SMHs) and travel agencies. According to Awang et al. (2015), SMHs can be defined as hotel with a rating of 3 stars and below, with 50 rooms or less, these encompass economy hotels, motels and small resorts. The proportion of SMHs in the hotel industry is believed to be roughly 35\% (409 hotels) of the total number of hotels in Egypt (1171) (Egyptian Tourism Chamber, 2016). Here, a sample of 800 frontline employees was targeted. In total, 467 copies were gathered, of which 445 were usable and only 22 were estimated invalid. As for travel agencies, the study focused on travel agencies category (A) as an example for tourism SME's in Egypt as indicated by previous studies (Abou-Shouk et al. 2013; Elsetouhi, et al. 2018; Elbaz \& Haddoud, 2017). There have been 1302 travel agencies operating in Egypt (Tourism in Figure, 2015). Within those entities, the study selected a sample of 600 frontline employees from travel agencies category A. The collection returned 364 copies, of which 343 were usable and only 23 were deemed invalid. Overall, 833 responses were gathered (59.5\% as a response rate), of which there were 788 valid ones and 45 were considered non-usable.

Table 1 indicates the sample characteristics. Table 1 shows the frontline employees of the tourism and hospitality SMEs involved in the sample were mostly 36 to 45 years old (60.7\%), followed by the 26-35 year-old age group (21.1\%). As for gender, a considerably higher percentage of males were recorded (approx. 78.9\%). In the Middle East and North Africa regions, this is very common, where the male population generally dominates the workforce (Elbaz \& Haddoud, 2017). We attribute this result to the low participation of women in the workforce. The Egyptian Centre for Economic and Social Rights (ECESR) (2013) claimed that "the Egyptian women labour force participation rate is very low, hovering between $20 \%$ to $25 \%$, compared to a global average of 52\% during the 2000s" (cited in Nazierand Ramadan, 2016, p. 2). The vast majority of frontline employees of tourism and hospitality SMEs hold at least a bachelor's degree (97.0\%). The participants were mostly married (97.1\%), followed by single, never married (3\%). Moreover, $3.9 \%$ of the respondents' experience did not exceed 5 years, and $90 \%$ of the respondents' experience was 5 to 10 years. The table also shows that more than half the participants were working in hospitality $(57.8 \%)$, followed by $42.2 \%$, whom were frontline employees working at travel agencies. 
International Journal of Heritage, Tourism and Hospitality Vol. (12), No. (2/2), September, 2018 By: Faculty of Tourism and Hotels, Fayoum University, Egypt

Table 1. Sample's Characteristics

\begin{tabular}{|l|l|}
\hline Characteristics & Percent \\
\hline Gender & \\
\hline Male & 78.9 \\
\hline Female & 21.1 \\
\hline Age group & \\
\hline $18-25$ Years & 0.0 \\
\hline $26-35$ Years & 21.1 \\
\hline 36-45 Years & 60.7 \\
\hline 46-55 Years & 18.3 \\
\hline More than 55 Years & 0.0 \\
\hline Educational level & \\
\hline Bachelor degree & 97.0 \\
\hline Diploma & 3.0 \\
\hline Master's Degree & 0.0 \\
\hline Doctorate Degree & 0.0 \\
\hline Marital Status & \\
\hline Single & 7.0 \\
\hline Married & 93.0 \\
\hline Unmarried & 0.0 \\
\hline Widowed & 0.0 \\
\hline Divorced & 0.0 \\
\hline Work Experience & \\
\hline Less than 5 Years & 3.9 \\
\hline From 5-10 Years & 90.0 \\
\hline From 11-15 Years & 6.1 \\
\hline More than 15 Years & 0.0 \\
\hline Working place & \\
\hline Hotel & 57.8 \\
\hline Travel agency & 42.2 \\
\hline
\end{tabular}

\section{Questionnaire development}

Five latent variables were employed in this paper: emotional exhaustion, cynicism, reduced professional efficacy, organizational commitment, and organizational performance. All constructs were measured using multiple indicators and each indicator used a 5-point Likert scale of 1 (strongly disagree) to 5 (strongly agree). Indicators were adapted from previous studies to ensure content validity. Further details for the questionnaire will be provided in appendix. Employees' burnout was measured employing the global measure of burnout (emotional exhaustion - 9 items, cynicism -5 items, reduced professional efficacy -8 items) developed by Maslach and Jackson (1986); Maslach et al. (1996) and Poghosyan, Aiken, and Sloane (2009). Organizational commitment was measured using five items adapted from scales developed by Mayer and Allen (1991) and Raman, Chadee, Roxas, and Michailova (2013). Performance was measured using five items adapted partially from Conger, Kanungo, and Menon (2000) and Elbaz and Haddoud (2017). The last part of the questionnaire encompasses the sample profile 


\section{Control variables}

The paper controlled for employees' age, education level, gender, marital status, working experience, working location. According to Waldman and Avilio (1986) concluded these demographics characteristics were found to substantially contribute to employees' job performance. Similarly, the study of Hassan and Olufemi (2014) revealed that salesmen employees' marital status and job tenure were found to be mostly predictive of performance.

\section{Analysis and Findings}

A variance-based structural equation modelling technique (anon-linear regressionbased PLS-SEM) was employed in this paper to test the hypotheses. The Warp PLS 6.0 software was used as it tolerates the building a complex theoretical model of a multi-block analysis (Kock, 2017). The use PLS-SEM was considered proper since the focus of this paper is to predict tourism and hospitality SMEs' performance. In this respect, PLS-SEM is characteristically adopted when the core objective of the research is to predict variance (Lowry and Gaskin, 2014). Moreover, as opposed to covariance-based approaches (CB-SEM), PLS-SEM techniques do not require a normal distribution, accordingly normality in the distribution was not checked for (Henseleret al., 2016). PLS-SEM, as stated by Henseler et al. (2009), minimizes the dependent variables residual variances. In addition, Lowry and Gaskin (2014) illustrated that as an SEM technique, PLS is suitable to examine mediation and interaction effects among the investigated variables.

\section{Measurement Model}

To meet the threshold of validity, two main validity subtypes are typically tested: (1) the convergent validity and, (2) the discriminant validity (Henseleret al., 2009). First, regarding convergent validity, Hair et al. (2016) suggest testing the average variance extracted (AVE). In addition, assessing collinearity issues with the variance-extracted factor (VIF) for all latent variables is essential (see Table 2). As for discriminant validity, Kock and Verville, (2012) claimed that the latter can be established when the extracted variance is larger than the squared correlation, and that the factors loading on their assigned variable are higher than their cross-loadings (Henseler et al., 2016). Hence, in the present study, we test the discriminant validity by establishing that the squared roots of AVE for each construct is greater than any of the correlations involving that construct as recommended by Hair et al. (2016).

Table 2. Composite reliability, Cronbach's alpha, AVE and VIFs coefficients

\begin{tabular}{|l|l|l|l|l|}
\hline Variables & $\begin{array}{l}\text { Composite } \\
\text { reliability }\end{array}$ & $\begin{array}{l}\text { Cronbach's } \\
\text { alpha }\end{array}$ & AVE & VIF \\
\hline EMO & 0.885 & 0.846 & 0.527 & 1.088 \\
\hline CYNICISM & 0.915 & 0.875 & 0.731 & 1.368 \\
\hline RED & 0.893 & 0.857 & 0.548 & 2.068 \\
\hline ORG & 0.919 & 0.890 & 0.696 & 2.037 \\
\hline PERFORM & 0.895 & 0.822 & 0.740 & 2.316 \\
\hline
\end{tabular}

Note: $\mathrm{EMO}=$ Emotional Exhaustion, $\mathrm{CYN}=$ Cynicism, RED = Reduced Professional Efficacy, ORG = Organizational Commitment, and PER $=$ Performance.

Table 2 indicates that both composite reliability and Cronbach's alpha values for all constructs are greater than 0.70, which are acceptable (Hair et al., 2016), and indicates sufficient reliability (MacKenzie, Podsakoff, \& Podsakoff, 2011). Moreover, all AVEs met the 0.5 minimum assessment for convergent validity and all factors' loadings are greater than the 0.5 threshold (Hair et al., 2016) (see Table 2). Moreover, 
Table 3 clarifies that the square root of AVE of each construct is greater than any of the other correlations involving that construct (Fornell \& Larcker 1981). Furthermore, Table 2 demonstrates that the VIFs values of all constructs were less than five, denoting the absence of both multicollinearity and common methods bias (Kock \& Lynn, 2012). Based on Tables 2 and 3, it can be confirmed that the study constructs have acceptable and sufficient discriminate validity.

Table 3. Squared roots of AVE

\begin{tabular}{|l|l|l|l|l|l|}
\hline Variables & 1 & 2 & 3 & 4 & 5 \\
\hline (1) EMO & $(0.726)$ & & & & \\
\hline (2) CYN & -0.047 & $(0.855)$ & & & \\
\hline (3) RED & 0.081 & -0.138 & $(0.740)$ & & \\
\hline (4) PER & -0.246 & -0.030 & -0.309 & $(0.786)$ & \\
\hline (5) ORG & -0.211 & 0.352 & -0.601 & 0.443 & $(0.860)$ \\
\hline
\end{tabular}

Note: Boldface values show the square roots of AVE..

\section{Structural Model and Hypotheses Testing}

Based on the measurement model, the confirmation for the validity and reliability of each construct used in this paper has been met. Thus, we proceed to the analysis of the structural model. Here, the path coefficients $(\beta)$, the $\mathrm{p}$ values and the $\mathrm{R}^{2}$ values of the present model are illustrated in Figure 2. In addition, the effect size $\left(\mathrm{f}^{2}\right)$ is also considered. Calculated as $\mathrm{f}^{2}=\left(\mathrm{R}^{2}\right.$ included $-\mathrm{R}^{2}$ excluded $) /\left(1-\mathrm{R}^{2}\right.$ included) (Henseleret al.,2009), it considers whether an exogenous variable has a small, medium, or great effect at the structural level (Roldán and Sanchez-Franco, 2012). In addition to the previous criteria, checking the relative effect of the predictive power of the exogenous variables is also deemed suitable (Stone-Geisser's $Q^{2}$ test) (Kock, 2017). Hair et al. (2016) contended that for the proposed model to have a predictive power $\mathrm{Q}^{2}$ must exceed 0 , while a $\mathrm{Q}^{2}$ fewer than 0 implies that the proposed model is poor in achieving predictive power.

The current results show the influence of employee burnout on tourism and hospitality SMEs' performance. Emotional exhaustion has a strong negative effect on tourism and hospitality SME performance $(\beta=-0.46$ and $\mathrm{P}<0.01$, medium effect size $=0.22$ ), while reduced professional efficacy was also found to have a strong effect on tourism and hospitality SME performance $(\beta=-0.30$ and $\mathrm{P}<0.01$, medium effect size $=0$. 0.11 ). However, cynicism was found to have a medium effect on tourism and hospitality SME performance $(\beta=-0.45$ and $\mathrm{P}<0.01$, medium effect size $=0.21)$. Accordingly, the paper accepts $\mathrm{H} 1, \mathrm{H} 2$ and $\mathrm{H} 3$. This signifies that employees' burnout diminishes (emotional exhaustion, cynicism and reduced professional efficacy) organisational performance (see Figure 2). Besides, to test the moderating influence of organisational commitment, a multi-group analysis was applied (Sharma, Borna, \& Stearns, 2009; Elbaz, Agag, \& Alkathiri, 2018). The results of the analysis are demonstrated in Table 4 and Figures 3 and 4 . Here, in order to accurately examine the moderating role of organizational commitment, the present paper adopted the formula used by Chin et al. (2003) to test the differences in path coefficients between the high level of organizational commitment subgroup model and the low level of organizational commitment subgroup model. Regarding the explained variance, it can be concluded that the model explains $35 \%\left(\mathrm{Q}^{2}=0.310\right)$ of the variance in leisure participation, $11 \%\left(\mathrm{Q}^{2}=0.107\right)$ of the variance in cynicism, $1 \%\left(\mathrm{Q}^{2}=0.013\right)$ of the variance in emotional exhaustion, $32 \%\left(\mathrm{Q}^{2}=0.306\right)$ of the variance in reduced professional efficacy, and $53 \%\left(\mathrm{Q}^{2}=0.524\right)$ of the variance in tourism and hospitality SME performance. 
International Journal of Heritage, Tourism and Hospitality Vol. (12), No. (2/2), September, 2018 By: Faculty of Tourism and Hotels, Fayoum University, Egypt

Table 4. Results of individual moderating effects

\begin{tabular}{|c|c|c|c|}
\hline \multicolumn{4}{|c|}{ Organizational commitment as a moderator } \\
\hline & & $\begin{array}{l}\text { Path of high- } \\
\text { level } \\
\text { commitment } \\
\text { subgroup } \\
\left(\mathrm{R}^{2}=0.17\right)\end{array}$ & $\begin{array}{l}\text { Path of low- } \\
\text { level } \\
\text { commitment } \\
\text { subgroup } \\
\left(\mathrm{R}^{2}=0.74\right)\end{array}$ \\
\hline Main effect & $\begin{array}{l}\text { Hypothesized moderating } \\
\text { effect }\end{array}$ & $\begin{array}{l}\text { Male group } \\
(\mathrm{n} 1=421)\end{array}$ & $\begin{array}{l}\text { Female group } \\
(\mathrm{n} 2=367)\end{array}$ \\
\hline $\mathrm{EMO} \longrightarrow \mathrm{PER}$ & $\begin{array}{l}\text { H4: High-level of } \\
\text { organizational } \\
\text { commitment reduces the } \\
\text { impact of employees' } \\
\text { emotional exhaustion on } \\
\text { tourism and hospitality } \\
\text { SMEs performance than } \\
\text { low-level of } \\
\text { organizational } \\
\text { commitment. }\end{array}$ & $\begin{array}{l}\beta=-0.47(\mathrm{P}< \\
0.01)\end{array}$ & $\begin{array}{l}\beta=-0.49(\mathrm{P}< \\
0.01)\end{array}$ \\
\hline $\mathrm{CYN} \longmapsto \quad \mathrm{PER}$ & $\begin{array}{l}\text { H5: High-level of } \\
\text { organizational } \\
\text { commitment reduces the } \\
\text { impact of employees' } \\
\text { cynicism on tourism and } \\
\text { hospitality SMEs } \\
\text { performance than low- } \\
\text { level of organizational } \\
\text { commitment. }\end{array}$ & $\begin{array}{l}\beta=0.22(\mathrm{P}< \\
0.01)\end{array}$ & $\begin{array}{l}\beta=0.45(\mathrm{P}< \\
0.01)\end{array}$ \\
\hline $\mathrm{RED} \longrightarrow \mathrm{PERF}$ & $\begin{array}{l}\text { H6: High-level of } \\
\text { organizational } \\
\text { commitment reduces the } \\
\text { impact of employees' } \\
\text { professional exhaustion } \\
\text { on tourism and hospitality } \\
\text { SMEs performance than } \\
\text { low-level } \\
\text { organizational } \\
\text { commitment. }\end{array}$ & $\begin{array}{l}\beta=-0.00(\mathrm{P}= \\
0.50)\end{array}$ & $\begin{array}{l}\beta=-0.55(\mathrm{P}< \\
0.01)\end{array}$ \\
\hline
\end{tabular}

Note: $\mathrm{EMO}=$ Emotional Exhaustion, $\mathrm{CYN}=$ Cynicism, RED $=$ Reduced Professional Efficacy, ORG $=$ Organizational Commitment, and PER = Job Performance. 
International Journal of Heritage, Tourism and Hospitality Vol. (12), No. (2/2), September, 2018 By: Faculty of Tourism and Hotels, Fayoum University, Egypt

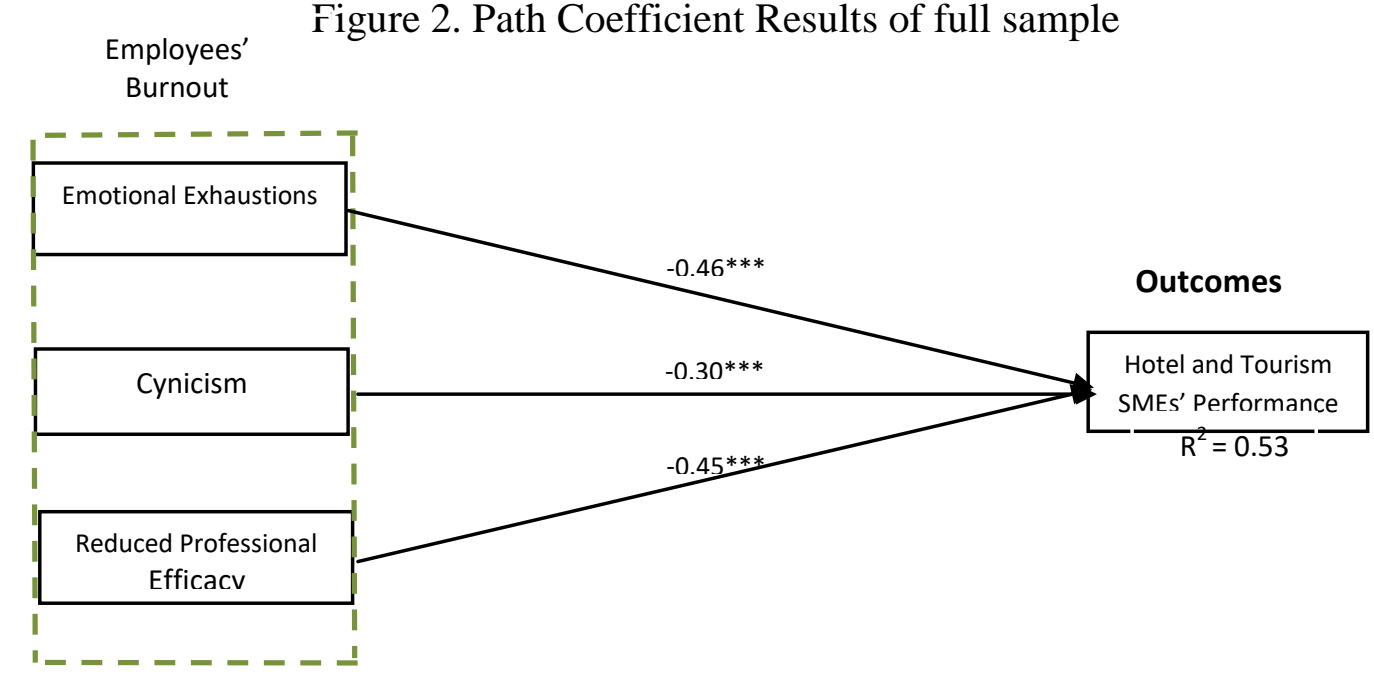

Note: The asterisks represent the level of significance of the coefficient. *0.05; **0.01;***0.001

Figure 3. Path Coefficient Results of high-level of organizational commitment

Employees' subgroup sample.

Burnout

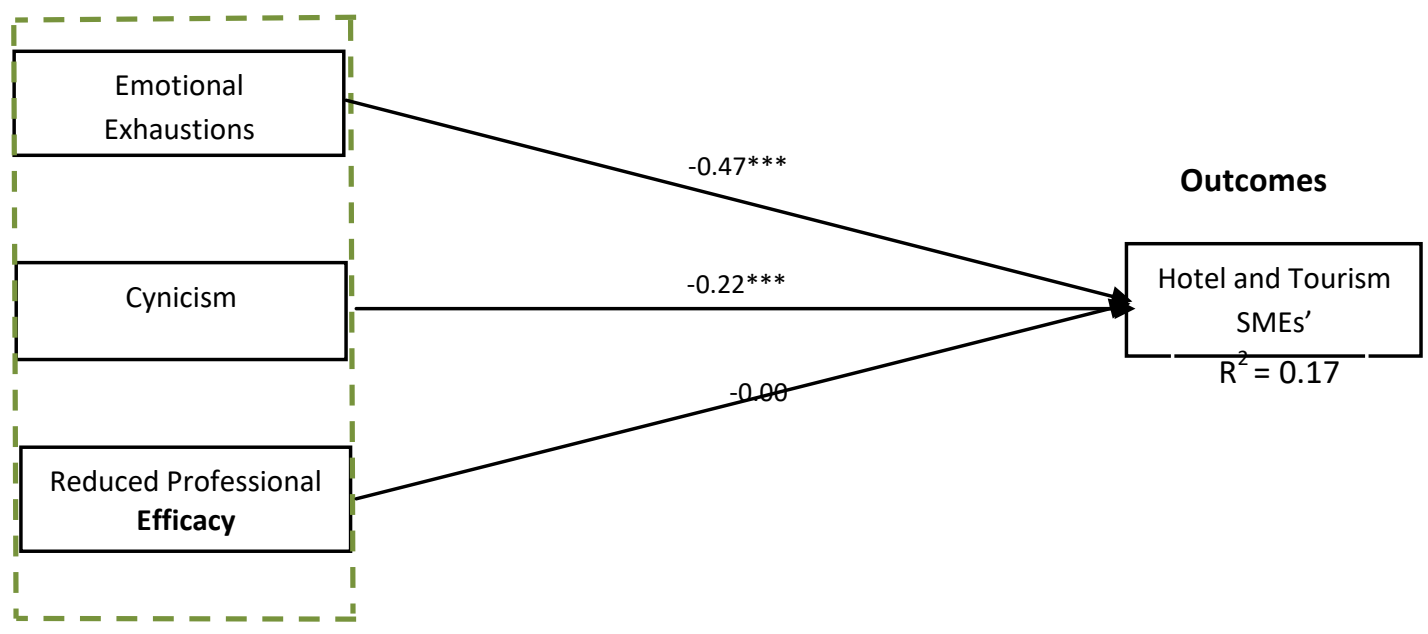

Note: The asterisks represent the level of significance of the coefficient. $* 0.05 ; * * 0.01 ; * * * 0.001$

Figure 4. Paih Coefficient Results of low-level of organizational commitment Emblovees' Burnout subgroup sample

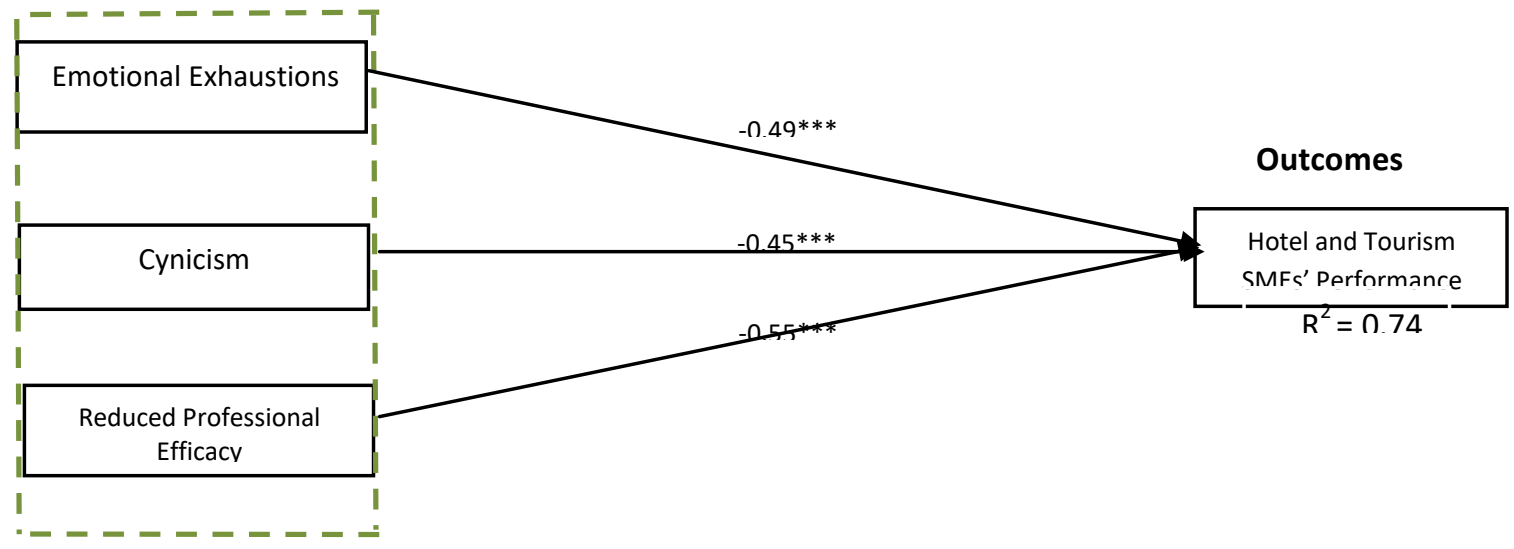

Note: The asterisks represent the level of significance of the coefficient. *0.05;**0.01;***0.001 
To conclude, Table 4 illustrates that a high level of organizational commitment diminishes the negative effect of emotional exhaustion, cynicism and professional efficacy on tourism and hospitality SME performance. In addition, figure 3 shows that a high level of organizational commitment subgroup model explains $17 \%\left(\mathrm{Q}^{2}=0.17\right)$ of the variance in tourism and hospitality SMEs performance. Conversely, a low level of organizational commitment raises the negative effect of emotional exhaustion, cynicism and professional efficacy on tourism and hospitality SME performance. Likewise, Figure 4 indicates that the low level of organizational commitment subgroup model explains $74 \%\left(\mathrm{Q}^{2}=0.74\right)$ of the variance in tourism and hospitality SME performance. Therefore, the paper accepts $\mathrm{H} 4, \mathrm{H} 5$ and $\mathrm{H} 6$.

\section{Discussion}

The aim of this study was to develop and investigate an integrative model that explains the impact of employees' burnout (emotional exhaustion, cynicism, reduced professional efficacy) on SMEs performance. In addition, this study examined whether organizational commitment influence the negative impact of employee burnout on Egyptian Tourism and Hospitality SMEs' performance. The model employed in this study used a highly representative sample of tourism and hospitality SMEs $(\mathrm{N}=788)$. Overall, the findings support the proposed model and demonstrate that employees' burnout was found to significantly decrease the performance of Egyptian tourism SMEs. As for the moderating influence of organisational commitment, the findings confirm the anticipated influence and show a high level of organizational commitment decreases, the negative influence of emotional exhaustion, cynicism and professional efficacy on tourism and hospitality SME performance. The following sub-sections discuss these results in further detail.

Regarding the negative influence of employee burnout on tourism and hospitality SME performance, the results are in line with Alarcon et al.'s (2009) findings suggesting that labour force that are facing continued pressure in the workplace and with a syndrome of emotional exhaustion and cynicism, will be negatively affected. The results are also congruent with Wright and Bonnet (1997) and Taris, (2006) and Holman (2002) who argued the existence of a significant and negative relationship between employees' emotional exhaustion, and subsequent work performance. Similarly, Schaufeli and Buunk (2003) and May et al. (2015) found that job burnout is the main cause of poor job performance, which is again confirmed in this study. Correspondingly, Shirom's (2003) findings found that employees' burnout negatively influences organizational turnover and commitment. With respect to the moderating role of organizational commitment, the results of the interaction model revealed that a high level of organizational commitment reduces the negative impact of emotional exhaustion, cynicism and professional efficacy on tourism and hospitality SME performance. This means that tourism and hospitality SMEs should dedicate considerable attention regarding the organizational commitment of employees as a determinant factor for employee performance. The present study confirms that employees, who are more committed, are less likely to suffer from burnout's negative consequences.

\section{Implications and Limitations}

The results obtained in this study hold important implications for both theory and practice. Theoretically, adopting the COR theory (Hobfoll 1989), in the study provides novel evidence on the role of a specific form of organisational commitment achievement, in decreasing the negative influence related to employees' emotional 
exhaustion, cynicism, reduced professional efficacy. More importantly, the paper uncovered the moderating influence of organizational commitment in reducing the negative influence of employees' burnout on performance. Hence, this finding sheds more light on the potential intervening factors likely to affect the influence of employees' strains and stress in the workplace. Practically, this investigation holds important implications for tourism and hospitality SME s in Egypt and the Middle East and North African (MENA) countries. Hotel tourism SMEs' managers are urged to place a higher emphasis on the level of employee commitment to achieve better organizational outcomes. Hence, managers can increase employees' commitment and retention by building a strong relationship between them and employees, providing effective communication, respect, benefits, feedback, creating learning opportunities and encouraging team building.

In terms of limitations, the following should be acknowledged. First, the present study conceptualised the consequences of employees' burnout on organisational performance. However, the negative influence of these factors may also be translated into a higher intention to leave rather than a weaker performance. Therefore, future research should test the influence of these factors on employees' intention leave. Additionally, employees' demographic characteristics may also influence the relationship between employees' burnout and organisational performance. Thus, future researchers can consider the role of such factors. In addition, the study encourages further research to explore with more depth the exogenous role of job satisfaction on burnout and performance since greater job dissatisfaction can increase employee burnout. Finally, we admit that the obtained findings may only be generalizable to tourism and hospitality SMEs operating in Egypt and the MENA region. Therefore, to validate our research findings at a wider scope, we ask for further investigations of our model in other developing and developed countries.

\section{References}

Abou-Shouk, M., Lim, W. M., \& Megicks, P. (2013) ' Internet adoption by travel agents: A case of Egypt', International Journal of Tourism Research, 15(3), 298312.

Agag, G., (2017) 'E-commerce Ethics and Its Impact on Buyer Repurchase Intentions and Loyalty: An Empirical Study of Small and Medium Egyptian Businesses', Journal of Business Ethics, 1-22, doi: 10.1007/s10551-017-3452-3.

Ahmad, A. (2010) 'Work-family conflict among junior physicians: its mediating role in the relationship between role overload and emotional exhaustion', Journal of Social Sciences, 6(2), 265-271.

Alarcon, G. Eschleman, K.J., \& Bowling, N. A. (2009) 'Relationship between Personality Variables and Burnout: A Meta-Analysis', Work and Stress, 23(3), 244-263.

Allen, N. J., \& Meyer, J. P. (1996) 'Affective, Continuance, and Normative Commitment to the Organization: an Examination of Construct Validity', Journal of Vocational Behavior, 49, 252-76.

Allen, N., \& Meyer, J. (1990) 'The measurement and antecedents of affective, continuance, and normative commitment to the organization', Journal of Occupational Psychology, 63(1), 1-18.

Awang, K. W., Aziz, Y. A., \& Samdin, Z. (2015) 'The growth of micro, small and medium-sized hotel enterprises: the hoteliers' perspectives', Journal of Technology Management and Business, 2(1), 34-47. 
Bakker, A. B., Demerouti, E., \& Sanz-Vergel, A. I. (2014) 'Burnout and work engagement: The JD-R approach. Annul Review Organizational Psychol. Organ. Behavior', 1(1), 389-411.

Bakker, A. B., Van Emmerik, H., \& Van Riet, P. (2008) 'How job demands, resources, and burnout predict objective performance: A constructive replication', Anxiety, Stress and Coping, 21(3), 309-324.

Burgess, J., \& Connell, J. (2006) 'Temporary work and human resources management: issues, challenges and responses', Personnel Review, 35 9(2), 129140 ,

Chelte, A. E., \& Tausky, C. (1986) 'A note on organizational commitment: antecedents and consequences among managers, professionals, and blue-collar workers', Work and Occupations, 13(4), 553-61.

Chen, S., Westman, M., \& Eden, D. (2009) 'Impact of enhanced resources on anticipatory stress and adjustment to new information technology: a fieldexperimental test of conservation of resources theory', Journal of occupational health psychology, 14(3), 219-234.

Chen, Z. X., Francesco, C. (2003). 'The relationship between the three components of commitment and employee performance in China', Journal of Vocational Behavior, 62(3), 490-510.

Conger, J. A., Kanungo, R. N., \& Menon, S. T. (2000). Charismatic leadership and follower effects. Journal of organizational behavior, 21(7), 747-767.

Deery, S., Iverson, R., \& Walsh, J. (2002) 'Work relationships in telephone call centres: understanding emotional exhaustion and employee withdrawal', Journal of Management Studies, 39(4), 471-496.

Deery, S., \& Kinnie, N. (2004) 'Introduction: The Nature and Management of Call Centre Work' in Deery, S and Kinnie, N. (eds), Call Centres and Human Resource Management, Palgrave, New York.

Elbaz, A. M., Agag, G. M., \& Alkathiri, N. A. (2018) 'How ability, motivation and opportunity influence travel agents performance: the moderating role of absorptive capacity', Journal of Knowledge Management, 22(1), in press.

Elbaz, A. M., Haddoud, M. Y. (2017) 'The role of wisdom leadership in increasing job performance: Evidence from the Egyptian tourism sector', Tourism Management, 63(2017), 66-76.

Elsetouhi, A. M., Hammad, A. A., Nagm, A. E. A., \& Elbaz, A. M. (2018) 'Perceived leader behavioral integrity and employee voice in SMEs travel agents: The mediating role of empowering leader behaviors', Tourism Management, 65(2018), $100-115$.

Egyptian Tourism Chamber Publication, (2016). Second issue, April. Cairo, Egypt.

Fornell, C., \& Larcker, D. (1981) 'Evaluating structural equation models with unobservable variables and measurement error', Journal of Marketing Research, 18(1981), 39-50

Francesco, A. M., \& Chen, Z. X. (2004) 'Collectivism in action: Its moderating effects on the relationship between organizational commitment and employee performance in China', Group and Organization Management, 29(4), 425-441.

Garg, P., \& Rastogi, R. (2006). 'New Model of Job Design: Motivating Employees' Performance', Journal of Management Development, 25 (6), 572-587.

Gemlik N, Sisman F. A., \& Unsal S. (2010) 'The Relationship between Burnout and Organizational Commitment among Health Sector Staff in Turkey', Journal of Global Strategic Management, 14, 7-12. 
Griffin, M.A., Parker, S.K., \& Mason, C.M. (2010). 'Leader vision and the development of adaptive and proactive performance: a longitudinal study', Journal of Applied Psychology. 95 (1), 174-82.

Han, S. J., Bonn, M. A., \& Cho, M. (2016) 'The relationship between customer incivility, restaurant frontline service employee burnout and turnover intention', International Journal of Hospitality Management, 52, 97-106.

Hair Jr, J. F., Hult, G. T. M., Ringle, C., \& Sarstedt, M. (2016) 'A primer on partial least squares structural equation modeling' (PLS-SEM). Sage Publications.

Henseler, J., Hubona, G., \& Ray, P. A. (2016) 'Using PLS path modeling in new technology research: updated guidelines', Industrial management and data systems, 116(1), 2-20.

Henseler, J., Ringle, C. M., \& Sinkovics, R. R. (2009) The use of partial least squares path modeling in international marketing. In New challenges to international marketing (pp. 277-319). Emerald Group Publishing Limited.

Hobfoll, S. E. (2001). The influence of culture, community and the nestedself in the stress process: Advancing conservation of resources theory', Journal of Applied Psychology, 50(3), 337-396.

Hobfoll, S. E. (2002) 'Social and psychological resources and adaptations', Review of General Psychology, 6(4), 302-324.

Hobfoll, S.E. (1989). 'Conservation of resources: A new attempt at conceptualizing stress', American Psychologist, 44(3), 513-524.

Hochwarter, W. A., Ferris, G. R., Zinko, R., Arnell, B., \& James, M. (2007) 'Reputation as a moderator of political behavior-work outcomes relationships: a two-study investigation with convergent results', Journal of Applied Psychology, 92(2), 567-579.

Holman, D., Chissick, C., \& Totterdell, P. (2002) 'The effects of performance monitoring on Emotional Labour and well-being in call centres' Motivation and Emotion, 26(1),18-31.

Jackson, S. E., Schwab, R. L., \& Schuler, R. S. (1986) 'Toward an understanding of the burnout phenomenon', Journal of Applied Psychology, 71, 630-640.

Jackson, S. E., Turner, J. A., \& Brief, A. P. (1987) 'Correlates of burnout among public service lawyers' Journal of Occupational Behavior, 8, 339-349.

Jaramillo, F., Mulki, J. P., \& Marshall, G. W. (2005) 'A meta-analysis of the relationship between organizational commitment and salesperson job performance:25 years of research, Journal of Business Research, 58, 705-714.

Kalliath, T. J., O'driscoll, M. P., \& Gillespie, D. F. (1998) 'The relationship between burnout and organizational commitment in two samples of health professionals', Work and Stress, 12(2), 179-185.

Keijsers, G. J., Schaufeli, W. B., Le Blanc, P. M., Zwerts, C., \& Reis-Miranda, D. (1995). 'Performance and burnout in intensive care units', Work and Stress, 9, $513-527$.

Kock, N. (2017) WarpPLS 5.0 user manual. Laredo, TX: ScriptWarp Systems.

Kock, N., \& Verville, J. (2012) 'Exploring free questionnaire data with anchor variables: an illustration based on a study of IT in healthcare', International Journal of Healthcare Information Systems and Informatics (IJHISI), 7(1), 46-63.

Lazaro, L., Shinn, M., \& Robinson, P. E. (1985) 'Burnout, performance and job withdrawal behavior', Journal of Health and Human Resources Administration, 7, 213-234. 
Lee, R.T., \& Ashforth, B. E. (1996) 'A meta-analytic examination of the correlates of the three dimensions of burnout', Journal of Applied Psychology, 81(2), 123-33.

Leiter, M. P. (1991) 'Coping patterns as predictors of burnout: The function of control and escapist coping patterns', Journal of Organizational Behavior,12, 123-144.

Leiter, M. P., \& Maslach, C. (1988) 'The impact of interpersonal environment on burnout and organizational commitment', Journal of Organizational Behavior, 9(4), 297-308.

Leiter, M. P., \& Maslach, C. (2004) 'Areas of worklife: A structured approach to organizational predictors of job burnout', In P. Perrewé \& D. C. Ganster, (Eds.), Research in occupational stress and wellbeing 3, 91-134. Oxford, UK: Elsevier.

Leiter, M. P., \& Maslach, C. (2005). Banishing burnout: six strategies for improving your relationship with work. San Francisco: Jossey-Bass.

Lin, J. H., Wong, J. Y., \& Ho, C. H. (2013) 'Promoting frontline employees' quality of life: leisure benefit systems and work-to-leisure conflicts', Tourism Management, 36(0), 178-187.

Lowry, P. B., \& Gaskin, J. (2014). Partial least squares (PLS) structural equation modeling (SEM) for building and testing behavioral causal theory: When to choose it and how to use it. IEEE Transactions on Professional Communication, 57(2), 123-146.

MacKenzie, S. B., Podsakoff, P. M., \& Podsakoff, N. P. (2011) 'Construct measurement and validation procedures in MIS and behavioural research: Integrating new and existing techniques', MIS quarterly, 35(2), 293-334.

Maslach, C. (1982). Burnout The Cost of Caring. Englewood Cliffs, NJ Prentice-Hall.

Maslach, C., \& Jackson, S.E. (1986) The Maslach Burnout Inventory. Consulting Psychologists Press, Palo Alto, CA.

Maslach, C., \& Leiter, M.P. (2005) 'Stress and burnout: the critical research in Cooper, C.L. (Ed.), Handbook of Stress Medicine and Health. CRC Press, Lancaster, pp. 155-172.

Maslach, C. (1979) The burn-out syndrome and patient care. In C. Garfield (Ed.), Stress and survival: The emotional realities of life-threatening illness (pp. 111120). St. Louis: Mosby.

Maslach, C. (1979) Burned-out. Psychiatric Nursing, November-December,. 5-9.

Maslach, C., \& Leiter, M. P. (1997). The truth about burnout. San Francisco: JosseyBass, pp. 38-44.

Maslach, C., Jackson, S. E., \& Leiter, M.P. (1996). Maslach Burnout Inventory Manual. 3rd ed., Consulting Psychologists Press, Palo Alto, CA.

Maslach, C., Schaufeli, W., \& Leiter, M. P. (2001) Job burnout. Annual Review of Psychology, 52(1), 397-422.

Mathieu, J. E., \& Zajac D. (1990) A review and meta-analysis of the antecedents, correlates, and consequences of organizational commitment. Psychological Bulleting, 108(2), 171-194.

May, R.W., Bauer, K.N., \& Fincham, F.D. (2015) School burnout: Diminished academic and cognitive performance. Learning and Individual Differences, 42(2015), 126-131.

Meyer, J. P., \& Allen, N. J. (1991) A three-component conceptualization of organizational commitment. Human Resource Management Review, 1(1), 61-89.

Meyer, J. P., \& Allen, N. J. (1997) Commitment in the workplace: Theory, research, and application. Sage.

Morrow, P.C. (1993). The Theory and Measurement of Work Commitment, JAI, Greenwich, CT. 
Motowidlo, S. J., \& Van Scotter, J. R. (1994) 'Evidence that task performance should be distinguished from contextual performance', Journal of Applied Psychology, 79(4), 475-80.

Naff, K. C., \& Crum, J. (1999) Working for America: Does public service motivation make a difference? Review of Public Personnel Administration, 19(4), 5-16.

Nagar, K. (2012) Organizational commitment and job satisfaction among teachers during times of burnout. Vikalpa, 37(2), 43-60.

Naidoo, L. J., Decriscio, A., Bily, H., Manipella, A., Ryan, M., \& Youdim, J. (2012) 'The 2 x 2 model of goal orientation and burnout? The role of approach-avoidance dimensions in predicting burnout', Journal of Applied Social Psychology, 42(10), 2541-2563.

Nazier, H., Ramadan, R. (2016) 'Women's participation in labor market in Egypt: Constraints and Opportunities', The Economic Research Forum (ERF), Egypt.

Parker, P. A., \& Kulik, J. A. (1995) 'Burnout, self and supervisor-related job performance, and absenteeism among nurses', Journal of Behavioral Medicine, 18(6), 581-599.

Pienaar, J., \& Willemse. S. (2008) 'Burnout, engagement, coping and general health of service employees in the hospitality industry', Tourism Management, 29(6), 1053-1063.

Piercy, N. F., Cravens, D. W., Morgan, N. A. (1998) 'Salesforce performance and behaviour-based management processes in business-to-business sales organizations', European Journal of Marketing, 32(1/2), 79-100.

Pines, A., \& Aronson, E. (1988). Career Burnout: Causes and Cures. New York: Free Press.

Poghosyan, L., Aiken, L. H., \& Sloane, D. M. (2009). Factor structure of the Maslach burnout inventory: an analysis of data from large scale cross-sectional surveys of nurses from eight countries. International journal of nursing studies, 46(7), 894902.

Putti, J. M., Aryee, S., \& Phua, J. (1990). Communication relationship satisfaction and organizational commitment. Group and Organization Studies, 15(1), 44-52.

Raman, R., Chadee, D., Roxas, B., \& Michailova, S. (2013). Effects of partnership quality, talent management, and global mindset on performance of offshore IT service providers in India. Journal of International Management. 19 (4), 333-346.

Randall, M., \& Scott, W. A. (1988). Burnout, job satisfaction, and job performance. Australian Psychologist, 23(3), 335-347.

Roldán, J. L., \& Sánchez-Franco, M. J. (2012). Variance-based structural equation modelling: Guidelines for using partial least squares in information systems research. In M. Mora (Eds.), Research methodologies, innovations and philosophies in software systems engineering and information systems (pp. 193221). Hershey, PA: IGI Global.

Schaufeli, W. B., \& Buunk, B. P. (2003). Burnout: An overview of 25 years of research and theorizing. In M. J. Schabracq, J. A. M. Winnubst, \& C. L. Cooper (Eds.), Handbook of work and health psychology (pp. 383-425). Chichester: Wiley.

Sharma, D., Borna, S., \& Stearns, J.M. (2009). An investigation of the effects of corporate ethical values on employee commitment and performance: Examining the moderating role of perceived fairness, Journal of Business Ethics, 89(2), 251260. 
Shaw, J. B., Fields, M. W., Thacker, J. W., \& Fisher, C. D. (1993). The availability of personal and external coping resources: Thier impact on job stress and employee attitudes during organizational restructuring. Work and Stress, 7(3), 229-246.

Shaw, J. D., Delery, J. E., \& Abdulla, M. H. (2003). Organizational commitment and performance among guest workers and citizens of an Arab country. Journal of Business Research, 56(12), 1021-1030.

Shirom, A. (2003). Job-related burnout: A review. In J. C. Quick and L. Tetrick (Eds.), Handbook of occupational health psychology, (pp. 245-264). Washington, DC: American Psychological Association.

Skinner, A. S. (1996). A system of social science: papers relating to Adam Smith. OUP Catalogue.

Taris, T. (2006). Is there a relationship between burnout and objective performance? A critical review of 16 studies, Work \& Stress, 20(4), 316-334.

Wright, T. A., \& Bonnet, D. G. (1997). The contribution of burnout to work performance", Journal of Organizational Behavior, 18 (5), 491-9.

Wright, T. A. (1997). Job performance and organizational commitment, perceptual and motor skills, 85 (2), 447-50.

Yiing, L.H., \& Ahmad, K. Z. (2009). The moderating effects of organizational culture on the relationships between leadership behaviour and organizational commitment and between organizational commitment and job satisfaction and performance. Leadership and Organization Development Journal, 30(1) 